\title{
Post-source Decay Analysis of Novel Heterogeneous Sugar Branched Cyclodextrins by Using Matrix-assisted Laser Desorption/ Ionization Time-of-Flight Mass Spectrometry
}

\author{
Tohru Yamagaki, ${ }^{\text {a) }}$ Ken-ichi Hamayasu, ${ }^{\text {b) }}$ \\ Hitoshi Hashimoto, ${ }^{\text {b) }}$ and Hiroshi NAKANISHI, ${ }^{\text {c) }}$
}

(Received November 8, 2002; Accepted July 25, 2003)

\begin{abstract}
Novel heterogeneous cyclodextrin (CyD) compounds of 6-O-(4-O- $\alpha$-D-glucuronyl- $\alpha$-D-glucosyl)cyclomaltoheptaose (GlcU-Glc- $\beta$ CyD) and 6-O-( $N$-acetyl- $\beta$-D-glucosaminyl)cyclomaltoheptaose $($ GlcNAc- $\beta$ CyD) were analyzed by matrix-assisted laser desorption/ionization mass spectrometry (MALDI-MS). Since the branch sugar residues of these heterogeneous CyDs had different molecular weights from those of glucose residues, the product ions generated from the branch or CyD part could be distinguished by their PSD spectra. In the PSD spectrum of GlcU-Glc- $\beta$ CyD, the product ions, $\left[\mathrm{M}-\mathrm{Glc}_{3 \sim 5}+\mathrm{Na}\right]^{+},[\mathrm{M}-\mathrm{GlcU}+\mathrm{Na}]^{+}$, and $\left[\mathrm{M}-\mathrm{GlcU}-\mathrm{Glc}_{1 \sim 5}+\mathrm{Na}\right]^{+}$, were observed. The chemical species of $\left[\mathrm{M}-\mathrm{Glc}_{3 \sim 5}+\mathrm{Na}\right]^{+}$was generated by the two-site cleavage of the glycosyl linkages in the CyD part without cleavage of the branch. In the PSD spectrum of GlcNAc- $\beta \mathrm{CD},\left[\mathrm{M}-\mathrm{Glc}_{1 \sim 5}+\right.$ $\mathrm{Na}]^{+}$, and $\left[\mathrm{M}-\mathrm{GlcNAc}-\mathrm{Glc}_{1 \sim 4}+\mathrm{Na}\right]^{+}$ions were observed.
\end{abstract}

\section{Introduction}

Matrix-assisted laser desorption/ionization time-offlight mass spectrometry (MALDI-TOF MS) has been widely used to analyze biomolecules such as sugar chains, proteins, and DNA. Post-source decay (PSD) measurements are very useful in the sequential analysis of sugar residues for oligosaccharides and amino acids for peptides. Cyclic sugar chains of cyclomaltooligosaccharides (cyclodextrins, CyDs) and their sugar branched derivatives have been analyzed by MALDIMS and PSD measurements. ${ }^{1), 2)}$

Cyclodextrins are cyclic sugar compounds synthesized enzymatically from starch, and six to eight $\alpha$-Dglucose residues constitute $\alpha$-, $\beta$-, and $\gamma$-CyD. ${ }^{3)}$ Amylase from microorganisms of Bacillus macerans is called cyclomaltodextrin glucanotransferase, and synthesizes cyclodextrins. Amylase is an enzyme that cuts off starch hydrolysis, and it works as glycosyltransferase of a reverse reaction. Cyclodextrins have inner hydrophobic cavities and their diameters depend on the number of sugar residues. The cavities of CyDs can recognize the guest molecules stereoselectively depending on their diameters. ${ }^{4}$ Since the properties of various chemical compounds change in the CyD cavities by host-guest interaction, CyDs are widely used in foodstuffs, pharmaceutical chemicals, and so on. For

*a) Department of Chemistry, School of Science, The University of Tokyo (7-3-1 Hongo, Bunkyo-ku, Tokyo 113-0033, Japan)

E-mail: yamagaki@chem.s.u-tokyo.ac.jp

b) Bio Research Corporation of Yokohama, (Techno-Core 5F, Yokohama-Kanazawa High-thch Center, 1-1-1 Fuku-ura, Kanazawa-ku, Yokohama 236-0004, Japan)

c) Biological Information Research Center, National Institute of Advanced Industrial Science and Technology, (1-1 Higashi, Tsukuba, Ibaraki 305-8566, Japan) example, the solubility of steroids and some hydropho bicchemicalsinwaterisincreasedbyusingCyD. Vitamins and prostaglandins acquire chemical stability in the CyD cavity. Essences of CyD complexes have a low degree of volatility. ${ }^{5)}$ The host-guest interaction of CyDs is highly stereoselective. This property is applied to studies of stereoselective organic synthesis, analytical chemistry, and drug delivery systems. ${ }^{6)}$ Sugar branched CyDs were synthesized to produce new properties and additional functions to CyD compounds. Homogeneous sugar branch CyD derivatives ofglucosylCyDs (Glc-CyDs), maltosyl-CyDs (Glc ${ }_{2}-$ CyDs), and maltotriosyl-CyDs (Glc $\left.{ }_{3}-\mathrm{CyDs}\right)$, are the conventional ones; they are constituted by only $\alpha$-Dglucopyranose residues. Methods of analyzing these complex CyD compounds were desired. MALDI-MS is one useful technique for analyzing these compounds. Previously, we analyzed homogeneous sugar branched CyD compounds having different branch structures such as $\gamma$-CyD, maltosyl- $\alpha \mathrm{CyD}$, and diglucosyl $-\alpha \mathrm{CyD}$ by MALDI-PSD spectra, ${ }^{1}$ however, it was difficult to distinguish between the product ions generating from the branch and CyD part because they had the same $\mathrm{m} / z$ values.

In this paper, novel heterogeneous sugar branched CyDs were studied by using MALDI-PSD measurements. Until now, hexose branched CyD compounds have been studied, but other types of sugar branched CyDs such as glucuronic acid and glucosamine branched CyDs have not yet been studied. Glucuronic acid and glucosamine have different molecular weights from glucose. Using mass spectrometry, the difference of the molecular weight of the sugar residue at the branch is so evident that we can easily distinguish between the PSD ions with or without the part of branch in their chemical species. It would be useful to know the fragmentation mechanism of sugar branched cyclo-oligosaccharides in the PSD process. 


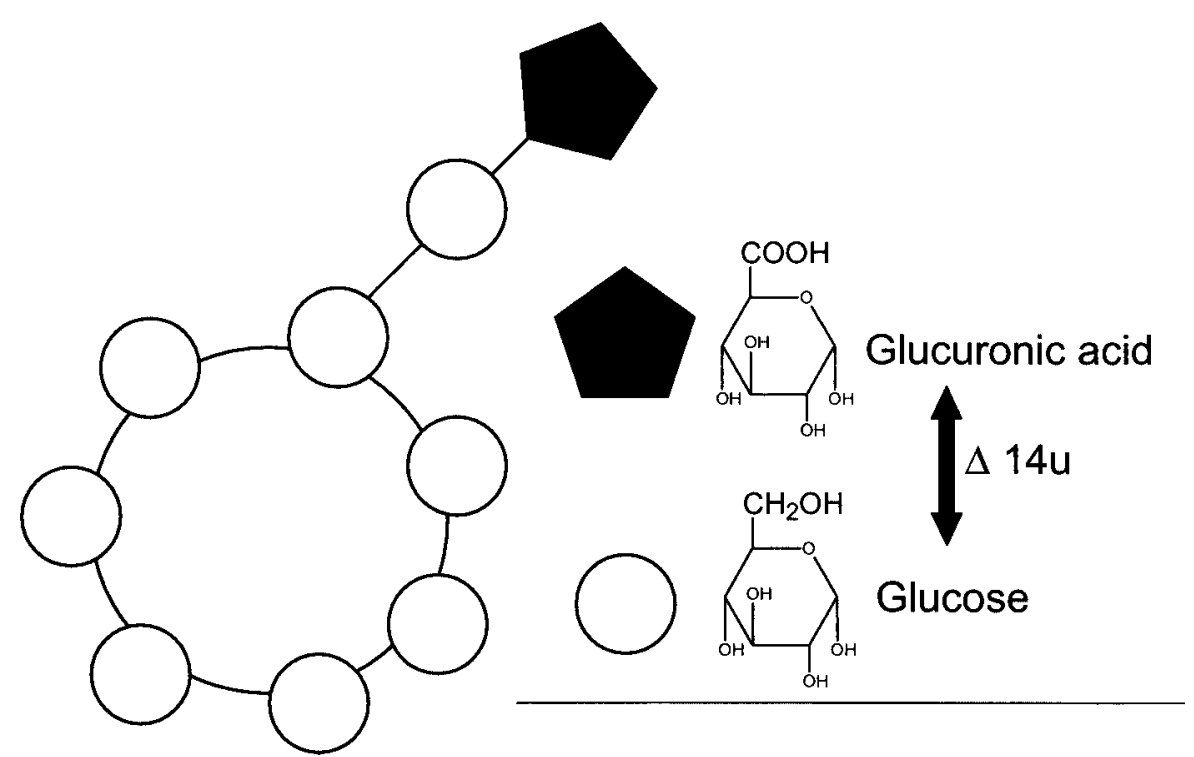

Fig. 1. Structure of GlcU-Glc- $\beta$ CyD.

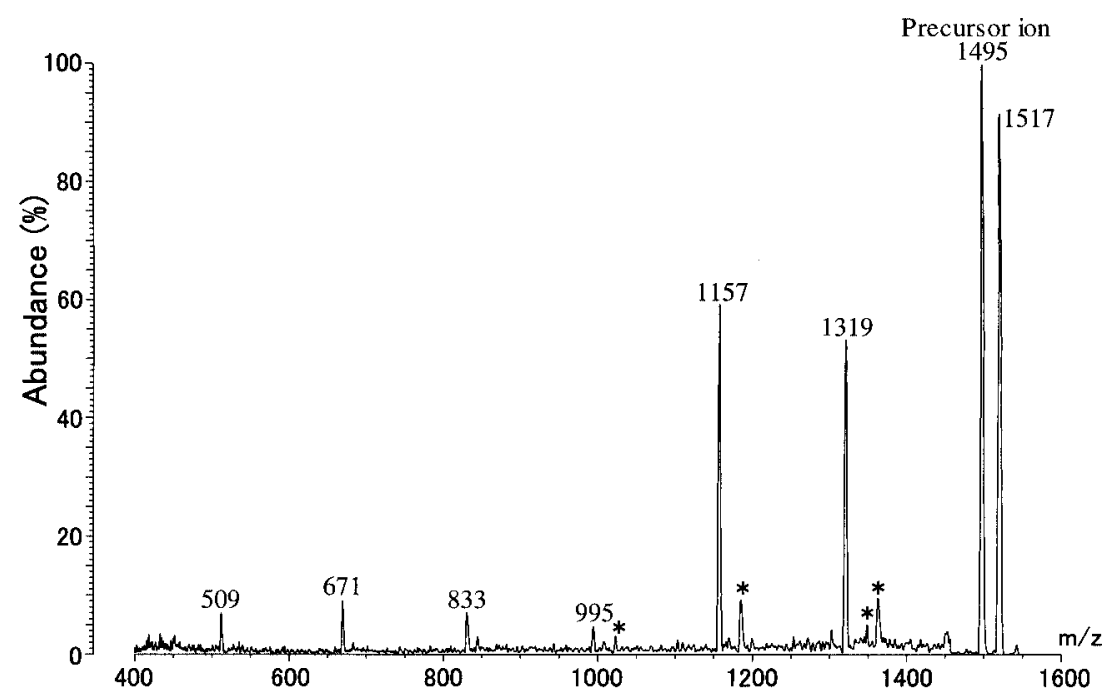

Fig. 2. The PSD spectrum of GlcU-Glc- $\beta$ CyD. The labeled ions by asterisk at $m / z 1361,1347,1185$, and 1023 were produced by the cross ring cleavages.

\section{Experimental}

A Kompact MALDI IV instrument with a curved field reflectron (Shimadzu Corp., Kyoto, Japan) was used to obtain MALDI-TOF and MALDI-PSD mass spectra. This type of device permits simultaneous focusing on a wide mass range of metastable fragment ions formed after acceleration in the ion source, even with a MALDI-TOF mass spectrometer.7), 8) These seamless PSD spectra have the great advantage of enabling one to discuss the relative abundance of the PSD ions.

The operating conditions were as follows: nitrogen laser $(337 \mathrm{~nm})$, acceleration voltage of $20 \mathrm{kV}$, a reflectron mode, positive ions detected. 2,5-Dihydroxybenzoic acid (DHBA) was used as a matrix in 10\% aqueous ethanol solution at a concentration of $10 \mathrm{mg} /$ $\mathrm{mL}$. The sample plate was painted with a sample solution of $0.5 \mu \mathrm{L}$ of the matrix solution, and then allowed to dry completely.
Each reported spectrum was the average of one to two hundred shots and was smoothed by the data system averaging function. To enable detection of the PSD ions, the laser power was adjusted to about $40 \mu \mathrm{J}$ to promote self-decay after acceleration. When reproducibility was checked under the same conditions described above, all the fragment ions were consistently observed. The reproducibility of the fragmentation patterns presented (including relative abundance) was satisfactorily high for the purposes of this study.

6-O-(4-O- $\alpha$-D-Glucuronyl- $\alpha$-D-glucosyl)cyclomaltoheptaose (GlcU-Glc- $\beta$ CyD) was a gift from Takeda Chemicals Co. 6-O-( $N$-Acetyl- $\beta$-D-glucosaminyl)cyclomaltoheptaose (GlcNAc- $\beta$ CyD) was enzymatically synthesized using $\mathrm{N}$-acetylhexosaminidase from the Jack bean. ${ }^{9)} \quad$ The curtailed structure of the samples are shown in Fig. 1.

\section{Results and Discussion}

In the spectrum of GlcU-Glc- $\beta$ CyD, two molecularrelated ions at $m / z 1495$ and 1517 were observed corre- 

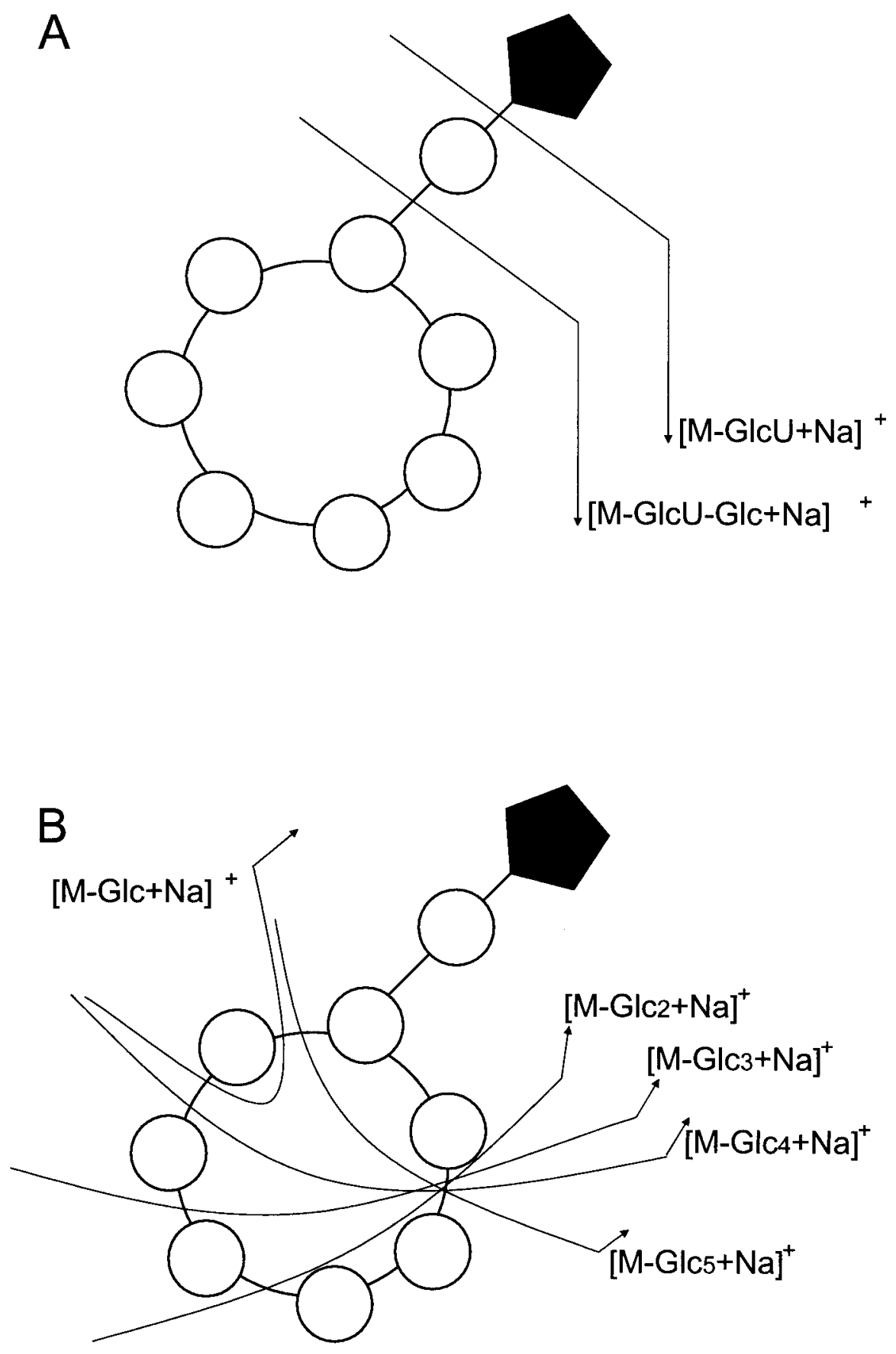

Fig. 3. Scheme of PSD of GlcU-Glc- $\beta$ CyD. The chemical species shown in (B) were one of the possible ones.

sponding to the chemical species of $[\mathrm{M}+\mathrm{Na}]^{+}$and $[\mathrm{M}-$ $\mathrm{H}+2 \mathrm{Na}]^{+}$, respectively. The glucuronic acid residue at the branch has a carboxyl group at C-6, so two types of sodium adducts formed (Fig. 1). The addition of sodium chloride promoted the formation of $[\mathrm{M}-\mathrm{H}+$ $2 \mathrm{Na}^{+}$. The PSD spectrum of GlcU-Glc- $\beta \mathrm{CyD}$ from the $[\mathrm{M}+\mathrm{Na}]^{+}$ion was almost the same as that from the $[\mathrm{M}$ $-\mathrm{H}+2 \mathrm{Na}]^{+}$ion.

Figure 2 is the PSD spectrum of GlcU-Glc- $\beta$ CyD from the ion at $m / z 1495[\mathrm{M}+\mathrm{Na}]^{+}$as a precursor ion. The product ions at $m / z 1319$ and 1157 had higher abundance than the other product ions. Therefore, these product ions were produced by the loss of the sugar residues at the branch. Previously, our analysis of $\mathrm{Glc}_{2}-\alpha \mathrm{CyD}$ demonstrated that the two product ions having higher $m / z$ values had higher abundance than the other product ions in the PSD spectrum of $\mathrm{Glc}_{2}-\alpha \mathrm{CyD}$. The number of higher ions corresponded to the length of the branch. In the FAB-MS studies of sugar branched CyDs, the product ions were only produced from the branch, ${ }^{10)-13)}$ because they were produced by one-site cleavage of the glycosyl linkage. The MALDI-PSD results and the interpretation did not conflict with the FAB-MS results. The intervals of the ions at $m / z 1495,1319$, and 1157 in the PSD spectrum of GlcU-Glc- $\beta$ CyD were $176 \mathrm{u}$ and $162 \mathrm{u}$, which corresponded to the loss of glucuronic acid residue and glucose residue. The chemical species of the ions at $m / z 1319$ and 1157 were $[\mathrm{M}-\mathrm{GlcU}+\mathrm{Na}]^{+}$and $[\mathrm{M}-$ $\mathrm{GlcU}-\mathrm{Glc}+\mathrm{Na}]^{+}$, respectively, and these product ions were produced by one-site cleavage of the glycosyl linkage at the branch (Fig. 3A). The product ions at 

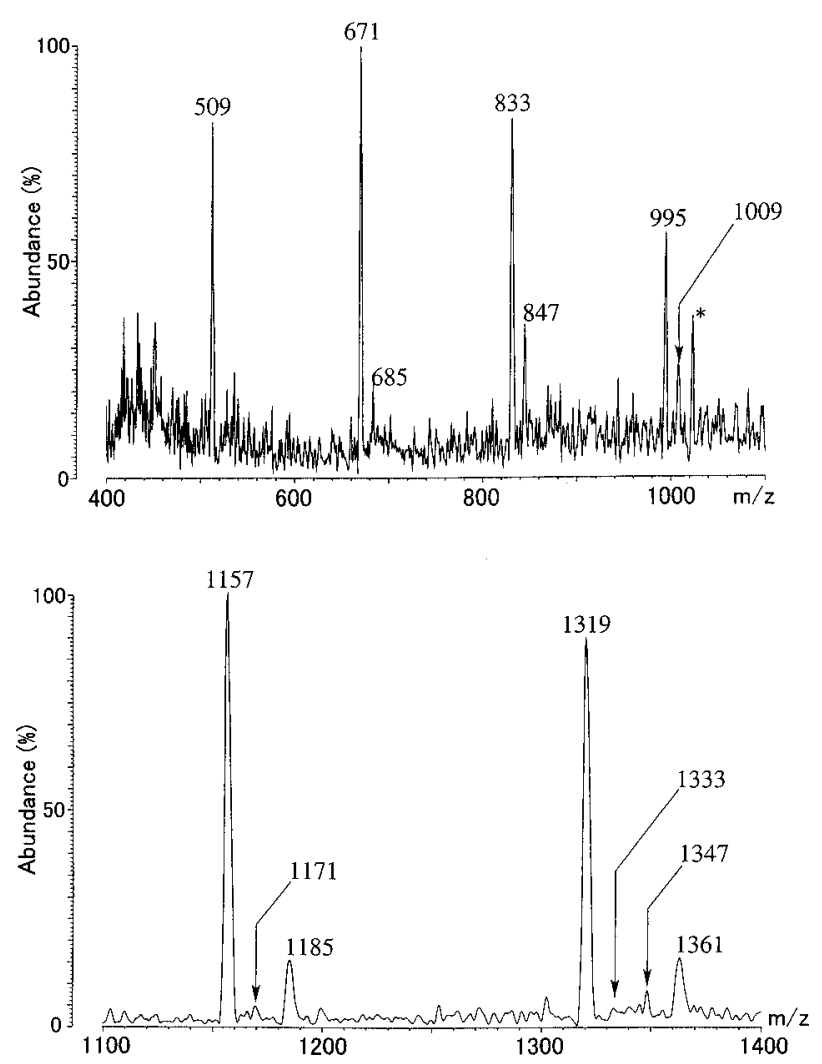

Fig. 4. Expanded PSD spectra of GlcU-Glc- $\beta C y D$. The labeled ion by asterisk at $\mathrm{m} / \mathrm{z} 1023$ was produced by the cross ring cleavages.

$m / z 995,833,671$, and 509 had lower abundance than the ions at $m / z 1319$ and 1157 . The chemical species of the product ions at $m / z 995,833,671$, and 509 were $\left[\mathrm{M}-\mathrm{GlcU}-\mathrm{Glc}_{2 \sim 5}+\mathrm{Na}\right]^{+}$, respectively. These results were consistent with our previous results of the analysis of homogeneous sugar branched CyDs. Based on the results of the analysis, we reached the following interpretation. In the PSD of sugar branched CyDs, the branched sugar residues would, at first, leave the molecule by one-site cleavage, then the sugar residues of the CyD part would leave by two-site cleavage of the glycosyl linkage at the CyD part.

The product ions at $m / z 1009,847$, and 685 had very low abundance (Figs. 2 and 4). Each ion interval was $162 \mathrm{u}$ and corresponded to the loss of glucose. Interestingly, these product ions also showed a mass interval value of $14 \mathrm{u}$ from the ions at $\mathrm{m} / z$ 995, 833, and 671 produced by the cleavage of the $\mathrm{CyD}$ part. The mass difference of $14 \mathrm{u}$ corresponded to the difference between the molecular weights of glucuronic acid and glucose (Fig. 1). The chemical species of the ions at $\mathrm{m} /$ $z 1009,847$, and 685 were $\left[\mathrm{M}-\mathrm{Glc}_{3 \sim 5}+\mathrm{Na}\right]^{+}$, respectively (Fig. 3B). Although the PSD ions corresponding to the chemical species $\left[\mathrm{M}-\mathrm{Glc}_{1}, \mathrm{Glc}_{2}+\mathrm{Na}\right]^{+}$were not observed clearly in this spectrum, the PSD ions $[\mathrm{M}-$
$\mathrm{Glc}+\mathrm{Na}]^{+}$at $m / z 1333$ and $\left[\mathrm{M}-\mathrm{Glc}_{2}+\mathrm{Na}\right]^{+}$at $m / z$ 1171 were thought to generate. The chemical species $\left[\mathrm{M}-\mathrm{Glc}_{1 \sim 5}+\mathrm{Na}\right]^{+}$still had the glucuronic acid at the branch even though one to five glucose residues were lost from the molecule. The glycosyl linkages at the CyD part had at least two-site cleavage before the linkages at the branch cleaved, and the glucose residues in the CyD part left the molecule without loss of the branch. These results were also observed in the PSD of other heterogeneous sugar branched CyDs such as GlcNAc-CyDs. When the PSD spectrum of GlcNAc$\beta C D$ was measured, the precursor ion at $\mathrm{m} / z 1360[\mathrm{M}+$ $\mathrm{Na}]^{+}$, the PSD ions $[\mathrm{M}-\mathrm{GlcNAc}+\mathrm{Na}]^{+}$and $[\mathrm{M}-$ GlcNAc $\left.-\mathrm{Glc}_{1 \sim 4}+\mathrm{Na}\right]^{+}$were observed at $\mathrm{m} / z 1157$, $995,833,671$, and 509. In addition, the PSD product ions $\left[\mathrm{M}-\mathrm{Glc}_{1 \sim 5}+\mathrm{Na}\right]^{+}(m / z \quad 1198,1036,874,712$, and 520), which were produced by the cleavage of the CyD part without the loss of the GlcNAc branch, were observed in the PSD spectrum of GlcNAc- $\beta$ CyD.

Heterogeneous sugar branched CyDs have sugar residues at the branch having different molecular weights from glucose, such as GlcU and GlcNAc. These compounds were very useful for distinguishing the product ions generating from the branch and the $\mathrm{CyD}$ part. This provided an excellent analysis of the PSD of sugar branched CyDs.

\section{References}

1) T. Yamagaki, Y. Ishizuka, S. Kawabata, and H. Nakanishi, Rapid Commun. Mass Spectrom., 10, 1887-1890 (1996).

2) H. Bartsch, W. A. Konig, M. Strabner, and U. Hintze, Carbohydr. Res., 286, 41-53 (1996).

3) A. Villiers, Compt. Rend., 112, 536 (1891)

4) M. V. Rekharsky and Y. Inoue, Chem. Rev., 98, 18751917 (1998).

5) A. R. Hedges, Chem. Rev., 98, 2035-2044 (1998).

6) K. Takahashi, Chem. Rev., 98, 2013-2033 (1998).

7) T. J. Cornish and R. J. Cotter, Rapid Commun. Mass Spectrom., 7, 1037-1040 (1993).

8) T. J. Cornish and R. J. Cotter, Rapid Commun. Mass Spectrom., 8, 781-785 (1994).

9) K. Hamayasu, K. Fujita, K. Hara, H. Hashimoto, T. Tanimoto, K. Koizumi, H. Nakano, and S. Kitahata, Biosci. Biotechnol. Biochem., 63, 1677-1683 (1999).

10) K. Koizumi, T. Tanimoto, Y. Okada, and N. Nakanishi, N. Kato, Carbohydr. Res., 215, 127-136 (1991).

11) K. Koizumi, T. Tanimoto, K. Fujita, K. Hara, N. Kuwahara, and S. Kitahata, Carbohydr. Res., 238, 75-91 (1993).

12) K. Koizumi, T. Tanimoto, Y. Okada, K. Hara, K. Fujita, H. Hashimoto, and S. Kitahata, Carbohydr. Res., 278, 129142 (1995).

13) K. Koizumi, T. Tanimoto, Y. Okada, S. Takeyama, K. Hamayasu, H. Hashimoto, and S. Kitahata, Carbohydr. Res., 314, 115-125 (1998).

Keywords: Cyclodextrin, Oligosaccharide, PSD, MALDI-MS 